\title{
Handheld Ultrasound Diagnosis Of Extremity Fractures
}

\author{
A J Brooks, V Price, M Simms, N Ward, C J Hand
}

Maj A Brooks FRCS

(Gen Surg) RAMC(V)

Trauma Surgery \& Critical Care Fellow

Division of Trauma and Surgical Critical Care University of

Pennsylvania Hospital Email:

adambrooks@doctors.org.uk

\section{Surg Lt V Price RN}

Senior House Officer in Accident \& Emergency Medicine

Frimley Park Hospital

Capt M Simms RAMC

Senior House Officer in Accident \& Emergency Medicine

Selly Oak Hospital

Maj NWard MRCSEd RAMC

Senior SHO

Orthopaedics

Queen Alexander

Hospital, Portsmouth

\section{Surg Cdr C Hand}

Consultant Trauma \& Orthopaedic Surgeon

Royal Hospital Haslar

\begin{abstract}
Hand portable ultrasound has been validated in trauma patients using the FAST technique. The machine's light and rugged design make it suitable for military deployment and they have been successfully used on deployments in Kosovo, Afghanistan and Iraq. Ultrasound is widely accepted in the diagnosis of abdominal and thoracic trauma, however, little work exists on its use in extremity trauma. Although the diagnosis of fractures usually relies on X-ray this may not be readily available at Role 1 or 2. We successfully identified long bone fractures in three patients using hand portable ultrasound during Operation Telic. The technique and ultrasound findings are described and the current literature on this technique is reviewed.
\end{abstract}

\section{Introduction}

The use of hand portable ultrasound, suitable for military deployment, has been validated in studies of trauma patients with abdominal injury (1) and haemothorax (2) and has been successfully used on deployments in Kosovo, Afghanistan and Iraq. FAST or Focussed Assessment with Sonography for Trauma $(3,4)$, is now widely accepted in the diagnosis of abdominal trauma in the emergency department and the ultrasound diagnosis of thoracic trauma including pneumothorax and haemothorax is well established $(5,6)$. In austere environments and on operational military deployment Xray may not always be readily available, because of constraints imposed by the need for mobility, size of equipment and availability of trained personnel. In these situations hand portable ultrasound, because of its weight, size and relative simplicity of use, may prove increasingly valuable as a tool in the diagnosis of a range of traumatic conditions (7).

There is limited data on the use of handheld ultrasound in the diagnosis of extremity trauma especially from operational deployment. We present a series of cases where hand portable ultrasound was used to successfully identify bony extremity trauma during Operation Telic.

\section{Case Report Technique}

Ultrasound imaging was undertaken using a SonoSite 180plus hand portable ultrasound system with a $7.5 \mathrm{MHz}$ linear transducer and the depth set to maximise visualisation of the cortical interface. Dynamic, real-time scanning was performed with the transducer initially scanning along the longitudinal plane. The cortex which is visible as an unbroken highly echogenic line, is assessed for interruptions or alterations in the bright signal.

The patients all gave informed consent to ultrasound examination and agreed to the publication of the images.

\section{Case 1}

A 20-year old soldier presented to the emergency department following a sporting accident with tenderness and deformity of the right tibia and fibula. Ultrasound revealed a cortical step (Figure 1) consistent with the fracture that was confirmed by X-ray (Figure 2).
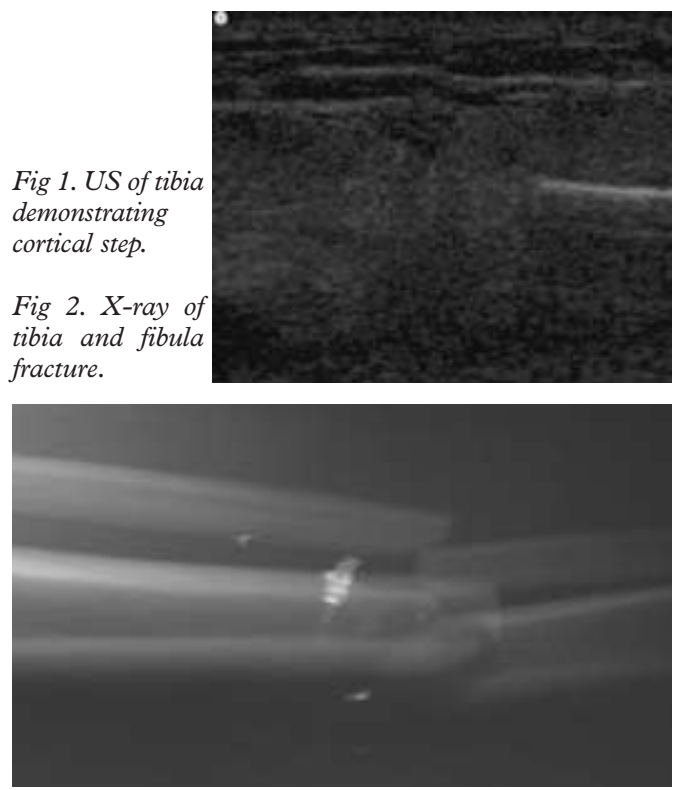

\section{Case 2}

The casualty had fallen on to his right arm from a moving vehicle and presented with significant bruising around the elbow. The haematoma initially made the images more difficult to diagnose, however, the displaced fracture was evident on ultrasound (Figures 3 and 4). 

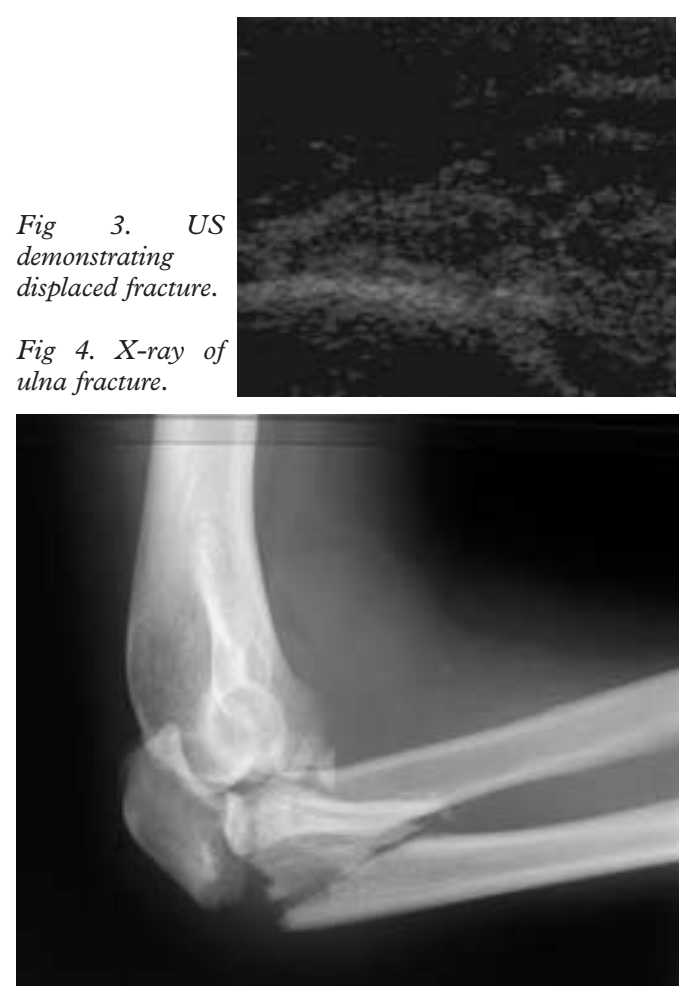

\section{Case 3}

The patient presented to the emergency department with a deformed left forearm sustained in a fall of 2 metres from a sanger. The ultrasound clearly demonstrated the fracture and angulation of the cortex that was subsequently confirmed by X-ray (Figures 5 and 6).
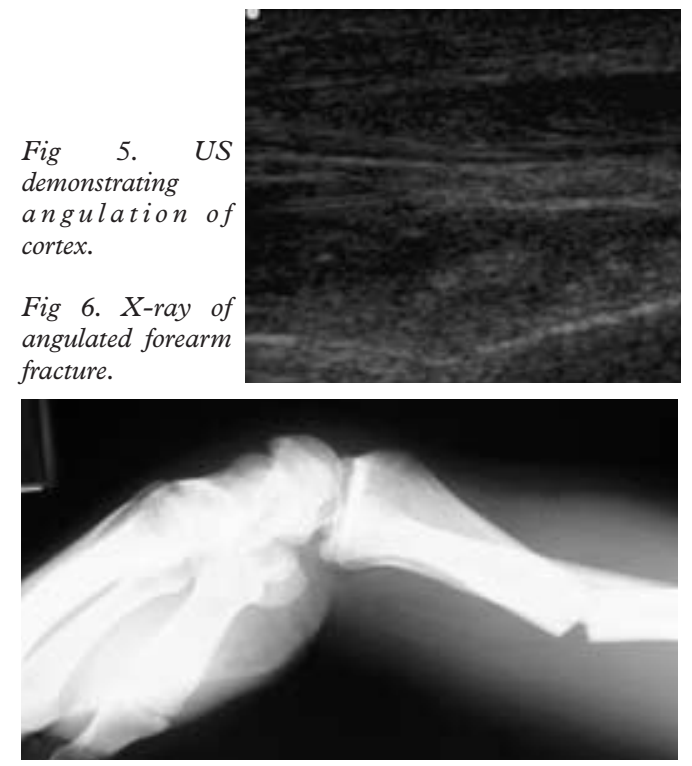

\section{Discussion}

Hand portable ultrasound for FAST evaluation of the injured casualty for abdominal haemorrhage has become a routinely deployed asset within the Defence Medical Services and training courses exist to teach military surgeons the FAST technique. Extremity trauma is common in the military and may arise either as a result of blunt or penetrating injury during both war fighting and the range of operations other than war on which the military deploy. Statistics compiled from the Wound Data and Munitions Effectiveness Team from the Vietnam War reveal that about $50 \%$ of combat casualties who survive to reach hospital have isolated extremity injury and $35 \%$ of these are isolated fractures of a long bone (8). Data from numerous other conflicts supports the high incidence of extremity wounds seen during combat (9).

The diagnosis of extremity trauma is usually based on the history, clinical examination and X-ray findings, however, currently this latter capability may not always be available until Role 3, even at forward deployed surgical facilities such as the Damage Control Surgical Team or Role 2+ facility. In the future mini portable digital Xray may be available at Role $2+$ and in this situation would remain the investigation of choice for bony injury. However, the routine deployment of hand portable ultrasound to Role $2 / 2+$ essentially for the rapid assessment of the abdomen by appropriately trained personnel would provide the opportunity for this technology to be used for the diagnosis of extremity fractures where X-ray is not available. Whilst the diagnosis of extremity fractures in the field may not necessarily determine long-term management of the fracture, accurate diagnosis of bony injury before the patient reaches Role 3 either by X-ray or by US could clearly be valuable. The use of US for the evaluation of bony injury during resuscitation at Role $2 / 2+$ may influence correct limb immobilization, early administration of adequate analgesia (10) appropriate fracture reduction and the timing of casualty evacuation. Theoretically in the future handheld US could also become available at Role 1 where it would provide similar advantages.

This study has confirmed the feasibility of extremity ultrasound in a military environment. There has previously only been a single case report of an ulna fracture that was successfully diagnosed with ultrasound on military deployment (11). Although the examples described in this report were clinically obvious, we have demonstrated that the technique is viable in the field. Further experience may confirm the value of US in the diagnosis of less apparent fractures. Previous data exists on the use of ultrasound in the evaluation of extremity injury. In a study of 95 patients (12), Dulchavsky demonstrated that extremity fractures could be identified with an accuracy of $94 \%$ using hand portable ultrasound. Using the technique that we have adopted, they showed that cortical disruptions of as little as $1 \mathrm{~mm}$ can be detected. A further report has suggested that early ultrasound diagnosis of a femoral fracture in the emergency room may allow early appropriate management and analgesia (10). Despite limited reports in ex- 
tremity trauma, ultrasound has been used more extensively for bony trauma in the diagnosis of sternal fracture $(13,14)$. These papers have shown conclusively that US can detect sternal fracture more accurately than X-ray.

The focussed use of ultrasound by nonradiologists is one of the keys to its successful application. Current ultrasound training focuses on abdominal trauma, however, if the diagnostic potential of ultrasound is to be increased then focussed training for thoracic and extremity trauma needs to be introduced. Dulchavsky showed that fractures could be detected with excellent accuracy even with minimal training (two hours of didactic and practical instruction) (12). The scans in our series were undertaken, following a short introductory course, under the supervision of a Consultant General Surgeon trained in the use of ultrasound and experienced in FAST.

\section{Conclusion}

Hand held ultrasound can successfully identify long bone fractures in an operational environment. A prospective study is required to evaluate the accuracy and value of this technique for the military. Further focussed training is required if ultrasound is to be used by non-radiologists on deployment to its full potential.

\section{Acknowledgements}

The authors wish to acknowledge the Drummond Foundation's support of research into the use of handheld ultrasound on deployment.

\section{References}

1. Brooks A, Davies B, and Connolly J. Prospective
Evaluation of Handheld Ultrasound in the Diagnosis of Blunt Abdominal Trauma. I Royal Army Med Corps 2002; 148(1): p. 19-22.

2. Brooks AJ, Davies B, Smethhurst J, et al. Emergency ultrasound in the acute assessment of haemothorax. Emerg Med fournal (in press).

3. Rozycki GS, Oschner MG, Jaffin JH, et al. Prospective evaluation of surgeons' use of ultrasound in the evaluation of trauma patients. F Trauma 1993; 34: p. 516-526.

4. Rozycki GS, Ochsner GM, and Schmidt JA. A prospective study of surgeon-performed ultrasound as the primary adjuvant modality for injured patient assessment. F Trauma 1995; 39: p. 492-500.

5. Dulchavsky SA, Hamilton DR, Diebel LN, et al. Thoracic ultrasound diagnosis of pneumothorax. $f$ Trauma 1999; 47(5): p. 970-1.

6. Dulchavsky, SA, KL Schwarz, AW Kirkpatrick, et al. Prospective evaluation of thoracic ultrasound in the detection of pneumothorax. F Trauma 2001; 50(2): p. 201-5.

7. Kirkpatrick AW and Brown DR. Hand-held portable sonography for the on-mountain exclusion of a pneumothorax. Wilderness Environ Med 2001; 12(4): p. 270-72.

8. Wound Data and Munitions Effectiveness Team, The WDMET Study. 1970

9. Roberts P. Patterns of injury in military operations. Current Anaesthesia \& Critical Care 2003; 13: p. 243-248.

10. Atkinson P and Lennon R. Use of emergency department ultrasound in the diagnosis and early management of femoral fractures. EMF, 2003; 20(4): p. 395.

11. Kirkpatrick AW, Brown R. Diebel LN, et al. Rapid diagnosis of an ulnar fracture with portable handheld ultrasound. Mil Med 2003; 168(4): p. 312-3.

12. Dulchavsky SA, Henry SE, Moed BR, et al. Advanced ultrasonic diagnosis of extremity trauma: the faster examination. $\mathcal{F}$ Trauma 2002; 53: p. 28-32.

13. Engin G, Yekeler E, Guloglu R, et al. US versus conventional radiography in the diagnosis of sternal fractures. Acta Radiol 2000; 41(3): p. 296-9.

14. Hendrich C, Finkewitz U, and Berner W. Diagnostic value of ultrasonography and conventional radiography for the assessment of sternal fractures. Injury 1995; 26(9): p. 601-04. 